\title{
The Italian Society for Industrial and Applied Mathematics
}

\author{
Luca Formaggia (Politecnico di Milano, Italy) and Nicola Bellomo (Politecnico di Torino, Italy)
}

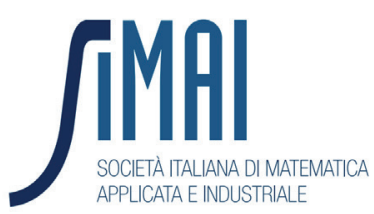

ber the 20th, 1988 by Vinish, was founded on DecemAlberto Tesei, and it has been operative since 1989.

It was a historical period in Italy with a strong impulse to research in applied mathematics, and the need for a collective organisation of the Italian community of applied mathematicians, both from the academic and industrial sectors, was strongly felt. It was decided that the managing board of the new Society would be formed by four members from academic and four from non-academic institutions to favour interactions and joint initiatives.

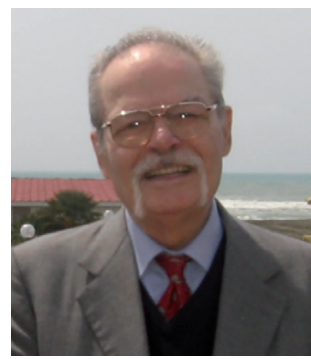

Vinicio Boffi (19272010), first President of SIMAI

Alberto Tesei, professor of analysis at the University of Rome "La Sapienza" and member of Accademia dei Lincei (the Italian Academy of Science), managed the Society until 1990, when the late Vinicio Boffi (1927-2010) was officially elected as the first president of SIMAI. Vinicio Boffi was a professor of mathematical physics at the University of Rome "La Sapienza", with primary research activity in kinetic theory and plasma physics, and a keen interest to applications of mathematics. He kept the presidency for two terms, until 2002, and was followed in that role by Mario Primicerio, Nicola Bellomo and Luca Formaggia.

The Society currently consists of around 350 members and collaborates with several other mathematical societies on an international and national level. In particular, it is a member of ECCOMAS, ICIAM and EMS and has a reciprocity agreement with SIAM. It has promoted the foundation of the Italian Federation for Applied Mathematics (FIMA), which combines, besides SIMAI, the other five Italian Associations (AIRO, AMASES, AIMETA, AICA, AILA) covering operations research, mathematical finance, computational mechanics, computer science and mathematical logic.

The primary mission of SIMAI has always been to foster active interaction among universities, research institutions, industries and schools in various fields of applied mathematics across a wide range of applications, including not only technological but also biomedical, economic and social sciences. This objective has been pursued in the last years by operating in several directions:

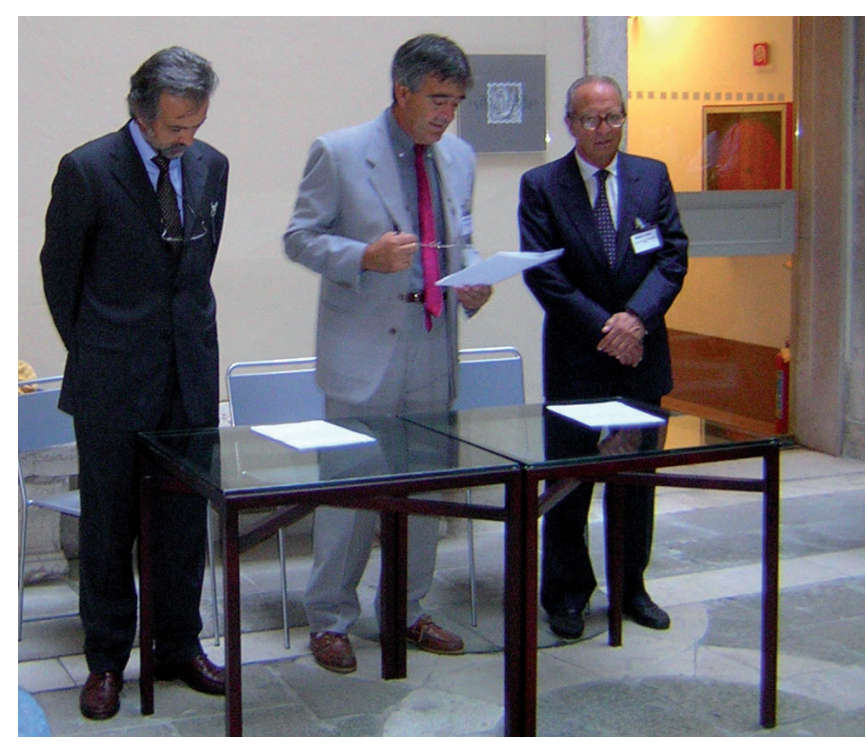

The former SIMAI President Mario Primicerio together with the Presidents of AIRO and AMASES announcing the foundation of the Italian Federation of Applied Mathematics Societies FIMA.

\section{Biennial SIMAI congress and workshop organisation}

Since 1992 SIMAI has organised a congress every two years which is open to international participants, with plenary talks given by key figures from the academic and industrial world and thematic sessions covering a wide range of applied and industrial mathematical topics. Special sessions are dedicated to specific aspects of industrial mathematics. For instance, at the latest congress in Rome, there was a special session on the application of mathematics to sport. The number of participants at the last congresses has reached a number between 400 and 500 , and the SIMAI congress is now the most important local event for Italian applied mathematicians. In 2010 , it was organised together with SEMA, the Spanish Society for Industrial Mathematics. Beside the biennial congress, SIMAI is active in hosting and sponsoring workshops and events. The cover of the booklet of SIMAII0 evente Biennial Congress, jointly organised with events in the past the Spanish Mathematical Society SEMA. 
few years were the joint meeting with the Italian Mathematical Union and the Polish Mathematical Society PTM, held in Wroclaw, Poland and the conference "Mathematics for Industry 4.0", with the participation of speakers from industry and academia. Recently, a special workshop was organised in Milan to celebrate thirty years since the foundation of SIMAI, with the involvement of representatives from the leading societies of applied and industrial mathematics in Europe and ICIAM.

\section{Prizes and awards}

The SIMAI Prize, recently renamed "Fausto Saleri Prize", and awarded every two years, is the most prestigious prize awarded by the association. The winner is chosen among young members who have given outstanding contributions to applied mathematics. Beside this main prize, SIMAI awards prizes to junior applied mathematicians, and participates with the Italian Mathematical Union (UMI) and the Istituto Nazionale di Alta Matematica "Francesco Severi" (INdAM) for a prize awarded for the best $\mathrm{PhD}$ thesis in pure and applied mathematics in Italian universities. The collaboration with ICIAM has been strengthened with the co-sponsorship of the prestigious Lagrange Prize.

\section{Editorial activity}

Communications in Applied and Industrial Mathematics (CAIM) is the official journal of SIMAI. The journal focuses on the applications of mathematics to the solution of problems in industry, technology, environment, cultural heritage and natural sciences, and is now indexed in Scopus. As a joint initiative with the Spanish Society of Applied Mathematics (SEMA) and Springer, the SEMA-SIMAI Springer Series was established to publish advanced textbooks, research-level monographs and collected works that focus on applications of mathematics to social and industrial problems, including biology, medicine, engineering, environment and finance. This series, which now numbers more than twenty volumes and is indexed in Scopus, is meant to provide useful reference material to students, academic and industrial researchers at an international level.
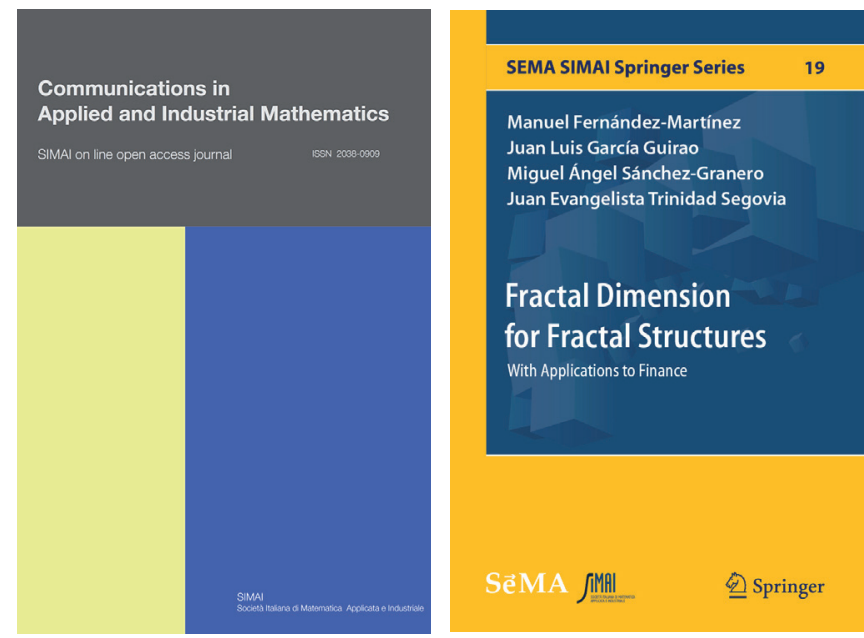

The cover of CAIM.

\section{Dissemination and outreach activities}

Since 2008, SIMAI sponsors and hosts the site Madd Maths (http://maddmaths.simai.eu), dedicated to the dissemination of mathematics and broadcasting through social media mathematical news to the general public, with particular attention to secondary school teachers. MaddMaths was an initiative by Roberto Natalini, a former member of the SIMAI Board, and now counts an editorial board of 25 members and many more contributors. In the last 15 years other associations (UMI, AIRO and recently AILA) have also joined SIMAI in sponsoring this endeavour, which is now an invaluable reference that reaches an audience well beyond that of professional mathematicians. The attention to secondary school teachers of mathematics has been strengthened in the last years, in the spirit of contributing to a renewal of mathematical education in Italy. Dedicated sessions were organised at the latest SIMAI biennial congresses, with the broad active participation of teachers.

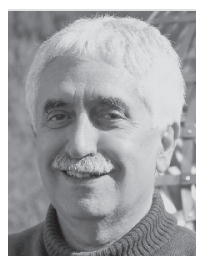

Since 1980 Nicola Bellomo has been a professor at Politecnico of Torino, Italy. His scientific activity covers nonlinear partial differential equations and modelling complex systems like traffic and crowds. He has coordinated several European research projects and delivered various distinguished lectures. He has been awarded the third level honour for scientific merits by the president of Italy, and since 2014 he has been ranked as a Highly Cited, Influential Mind by Clarivate, WEB of Science.

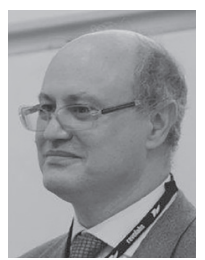

Luca Formaggia is the current president of SIMAI. After five years in the major Italian aerospace industry, he became head of the CFD unit at CRS4, a research centre in Cagliari, Italy to then move to EPFL as the first assistant to the chair of modelling and scientific computing and, finally, to Politecnico di Milano where he is professor of numerical analysis. His principal research interests are the numerical analysis of PDEs, multiphysics problems, scientific programming and industrial applications of mathematics. 